\title{
Early adolescent outcomes of joint developmental trajectories of problem behavior and IQ in childhood
}

\author{
Eirini Flouri ${ }^{1}$ [ $\cdot$ Efstathios Papachristou ${ }^{1} \cdot$ Emily Midouhas $^{1} \cdot$ Heather Joshi $^{2} \cdot$ George B. Ploubidis $^{2} \cdot$ Glyn Lewis $^{3}$
}

Received: 31 October 2017 / Accepted: 5 April 2018 / Published online: 16 April 2018

(c) The Author(s) 2018

\begin{abstract}
General cognitive ability (IQ) and problem behavior (externalizing and internalizing problems) are variable and inter-related in children. However, it is unknown how they co-develop in the general child population and how their patterns of codevelopment may be related to later outcomes. We carried out this study to explore this. Using data from 16,844 Millennium Cohort Study children, we fitted three-parallel-process growth mixture models to identify joint developmental trajectories of internalizing, externalizing and IQ scores at ages 3-11 years. We then examined their associations with age 11 outcomes. We identified a typically developing group (83\%) and three atypical groups, all with worse behavior and ability: children with improving behavior and low (but improving in males) ability (6\%); children with persistently high levels of problems and low ability (5\%); and children with worsening behavior and low ability (6\%). Compared to typically developing children, the latter two groups were more likely to show poor decision-making, be bullies or bully victims, engage in antisocial behaviors, skip and dislike school, be unhappy and have low self-esteem. By contrast, children (especially males) in the improver group had outcomes that were similar to, or even better than, those of their typically developing peers. These findings encourage the development of interventions to target children with both cognitive and behavioral difficulties.
\end{abstract}

Keywords IQ $\cdot$ Problem behavior $\cdot$ Joint trajectories $\cdot$ Externalizing problems $\cdot$ Internalizing problems $\cdot$ Cognitive ability

\section{Introduction}

Low levels of general cognitive ability (IQ) and high levels of problem behavior (internalizing and externalizing problems) in childhood are independently associated with many adverse outcomes in later life, including psychiatric disorders, all-cause mortality, morbidity, social exclusion and poverty [1-3]. IQ and problem behavior are variable [4, $5,6,7-15]$ and inter-related in children, with evidence for

Electronic supplementary material The online version of this article (https://doi.org/10.1007/s00787-018-1155-7) contains supplementary material, which is available to authorized users.

Eirini Flouri

e.flouri@ucl.ac.uk

1 Department of Psychology and Human Development, UCL Institute of Education, University College London, 25 Woburn Square, London WC1H 0AA, UK

2 Department of Social Science, UCL Institute of Education, University College London, London, UK

3 UCL Division of Psychiatry, University College London, London, UK substantial comorbidity between internalizing and externalizing problems [16] and for strong links between IQ and externalizing problems [17]. There is also some evidence for a longitudinal association between various cognitive skills and externalizing problems in the very early years [18], between specific cognitive skills and specific internalizing or externalizing problems at the end of the distribution of either [19, 20] or both [21-23], and between externalizing and internalizing problems $[6,24,25]$. However, the extent to which all three combine in the general child population and over time and whether their combinations are related to later outcomes have not been examined yet.

In this study, we aimed to address this gap by examining the co-development of internalizing problems, externalizing problems and IQ at ages 3-11 years (using three-parallelprocess growth mixture modeling) in a general child population cohort. We also tested how the various patterns of their co-development may be associated with behavioral, social and emotional outcomes in early adolescence (age 11 years). These were truancy, antisocial behavior, decision-making, bullying, school engagement, happiness and self-esteem. 


\section{Method}

\section{Sample}

The data for this study came from the first five sweeps of the Millennium Cohort Study (MCS), a population-based longitudinal cohort study of children born in the UK over 12 months from 1 September 2000. The children were around 9 months old at Sweep 1, and 3, 5, 7 and 11 years old at Sweeps 2, 3, 4 and 5, respectively. At Sweeps 1, 2, 3,4 and 5 , the number of productive families was 18,522 , $15,590,15,246,13,857$ and 13,287 , respectively. The analytic sample of our study included children (singletons and first-born twins or triplets) with valid data on problem behavior and IQ in at least one of Sweeps 2 (when these were first measured in MCS) to 5 ( $N=16,844 ; 51 \%$ male). Ethical approval was gained from NHS Multi-Centre Ethics Committees, and parents gave informed consent before interviews took place. Figure S1 in the Supplementary Material shows the flowchart of the study design.

\section{Measures}

\section{General cognitive ability (IQ) at ages 3, 5, 7 and 11 years}

IQ was calculated for each age by using the age-adjusted ability assessments that were available in MCS, as in Flouri et al. [26]. At age 3, there were two cognitive assessments, the Bracken School Readiness AssessmentRevised, which measures children's 'readiness' for formal education by testing their knowledge and understanding of basic concepts [27], and the second edition of the British Ability Scales (BAS) [28] for Naming Vocabulary, which measures expressive language. At age 5, ability was assessed with three scales: BAS Naming Vocabulary, BAS Pattern Construction (measuring spatial problem-solving) and BAS Picture Similarities (measuring non-verbal reasoning). At age 7, it was measured with BAS Pattern Construction, BAS Word Reading (measuring educational knowledge of reading) and the National Foundation for Educational Research Progress in Maths. At age 11, it was measured with BAS Verbal Similarities, which assesses verbal reasoning and verbal knowledge.

When multiple cognitive assessments were available (i.e., at ages 3, 5 and 7), IQ was measured using the scores derived from a principal components analysis of these assessments. Each component score was then transformed into a standardized IQ score with a mean of 100 and a standard deviation of 15 [29]. Multiple well-validated assessments are thought to be able to capture a higherlevel intelligence (' $g$ ') factor which is not dependent on the use of specific mental ability tasks [30]. For age 11, when only one measure of ability was available in MCS, we transformed the age-adjusted ability score into a standardized IQ score.

\section{Problem behavior (internalizing and externalizing problems) at ages 3, 5, 7 and 11 years}

Internalizing and externalizing problems were measured with the parent-reported Strengths and Difficulties Questionnaire (SDQ), a short behavioral screening tool for children aged 2-17 years [31]. The 20 difficulties and symptoms assessed by the SDQ are equally divided in four subscales: emotional symptoms, conduct problems, hyperactivity/inattention and peer problems. In line with the recommended practice for community samples [32], the internalizing problems scale comprised the ten items from the emotional and peer problems subscales, and the externalizing problems scale the ten items from the hyperactivity and conduct problems subscales. Scores on each of these two scales range from 0 to 20, with higher scores indicating more problems or symptoms.

\section{Behavioral, social and emotional outcomes at age 11 years}

We examined several outcomes at age 11 years, as follows. Decision-making was measured using the Cambridge Gambling Task (CGT) [33], described in detail in a previous study using it in MCS [34]. The CGT produces six outcomes, risk taking, quality of decision-making, deliberation time, risk adjustment, delay aversion and overall proportion bet. Bullying involvement was measured with two selfreport items: 'how often do other children hurt you or pick on you on purpose?' and 'how often do you hurt or pick on other children on purpose?' Following much previous research, we identified four mutually exclusive groups of bullying involvement based on children's answers to these questions: 'neutrals', bullies, victims and bully victims. (Both self-reported items were scored on six-point scales from $1=$ most days to $6=$ never. Participants who answered 'never' on both questions were classified as 'neutrals', those answering between ' 1 ' (most days) and ' 5 ' (less often than every few months) on the first and ' 6 ' (never) on the second were classified as 'victims', those answering between ' 1 ' and ' 5 ' on the second and ' 6 ' on the first were classified as 'bullies', and those whose answers on both questions ranged between ' 1 ' and ' 5 ' were classified as 'bully victims'.) Single item 'yes-no' questions were used to assess truancy ('Have you ever missed school without your parents' permission?') and smoking or drinking ('Have you ever had an alcoholic drink, that is, more than a few sips?' and 'Have you ever tried a cigarette, even if it was only a single puff?'). 
School engagement was assessed by means of a single item asking the child how much he or she likes school, on a scale from 1 (a lot) to 3 (not at all). A (un)happiness measure was derived by summing the MCS questions on how happy the child feels about six different domains, answered on a 7-point Likert scale from 1 (completely happy) to 7 (not at all happy). These domains included school work, appearance, family, friends, the school they go to and life as a whole (Cronbach's alpha $=0.83$ ). Children in the upper quintile of the summative score were classified as being unhappy. Antisocial behavior was measured by a positive response to engagement in behaviors such as being rude or noisy in public places, stealing, spraying graffiti or vandalizing. Finally, self-esteem was measured with the five items of the Rosenberg self-esteem scale [35] used in MCS (Cronbach's alpha $=0.74$ ). Higher scores on the scale (ranging 5-20) indicated lower self-esteem.

\section{Early childhood covariates}

We controlled for important early predictors of these outcomes as well as IQ and problem behavior in children [34, 36-38]. These were mother-reported socio-demographic, health and lifestyle characteristics at baseline (age 3 years), as follows: child's birth weight ( $<2.5 \mathrm{~kg}$ or not), breastfeeding status and ethnicity (white, Indian, Pakistani or Bangladeshi, black, mixed and other), maternal education (university degree or not), maternal smoking status, maternal age at child's birth, maternal psychological distress (assessed using the Kessler K6; Kessler et al. [58]), family structure (living with both biological parents or not) and socioeconomic disadvantage. This was measured (as in Malmberg and Flouri [40]) using a four-item summative index comprising overcrowding ( $>1.5$ people per room excluding bathroom and kitchen), lack of home ownership, receipt of income support and income poverty (equivalized net family income below $60 \%$ of the national median household income).

We also controlled for household chaos, parent-child relationship, parental involvement, quality of emotional support, harsh parental discipline and regular bedtimes, to account for parenting and the home environment at the age 3 baseline. Household chaos was assessed with a 3-item parent report of how calm and organized the atmosphere at the home is (Cronbach's alpha $=0.68$ ). Parent-child relationship was assessed using the closeness and conflict scales of the Pianta Child-Parent Relationship Scale which comprises 15 items rated on 5-point Likert scales assessing the parent's perception of their relationship with their child [41]. Parental involvement was assessed with a single item on whether the responding parent reads to their child daily or almost daily. Quality of emotional support was measured using 9 items (Cronbach's alpha $=0.61$ ) of the short form version of Caldwell and Bradley's Home Observation for
Measurement of the Environment scale [42]. This was a continuous scale ranging $0-9$ (with a higher score indicating lower quality) which we dichotomized to 0 vs. $\geq 1$ in view of its severe skewness $(59 \%$ had a score of $0,28 \%$ had a score of 1 and the remaining $13 \%$ had a score $\geq 2$ ). Harsh parental discipline was measured using three items (Cronbach's alpha $=0.66)$ of the Conflict Tactics Scale [43], asking the parent whether they smack, tell off or shout at the child when he or she misbehaves, with answers ranging from 1 (never) to 5 (daily). Finally, regular bedtimes were assessed by a single item asking whether the child has regular bedtimes. Children whose parent responded 'sometimes', 'almost never' or 'never' were classified as having an irregular bedtime schedule.

\section{Analytic strategy}

All analyses were stratified by sex in light of the evidence for sex differences in the developmental trajectories of both IQ and problem behavior in childhood [44-47]. In all models, the MCS sampling stratum was controlled to account for the disproportionate stratification of the MCS survey design. All analyses were performed in Stata/SE 14.2 [48] and Mplus 7.4 [49].

To describe the trajectories of internalizing problems, externalizing problems and IQ from ages 3-11 years, we fitted a three-parallel-process growth mixture model (GMM; [50]). In a parallel-process GMM, the growth parameters, i.e., the slope and intercept, are estimated for each of the repeatedly measured variables. Also estimated is a latent class variable, defined by the growth parameters of the parallel processes. We estimated models with 1-6 classes and compared model fit with four commonly used goodness of fit indices [51]: (1) the Bayesian information criterion (BIC); (2) the sample size-adjusted BIC (SSABIC); (3) the Akaike information criterion (AIC) and (4) the entropy of each model. Lower BIC, AIC and SSA-BIC values indicate better fit to the data. Entropy ranges from 0 to 1 , with higher values indicating that the latent classes are clearly distinguishable (values $\geq 0.80$ are considered adequate). Solutions with extremely small classes $(\leq 1 \%$ of the sample) or with several small classes $(<2 \%$ of the sample) were deemed potentially unstable and thus disregarded. The GMM was carried out using the maximum likelihood with robust standard errors estimator, which is robust to non-normality in the data. Full information maximum likelihood (FIML) was used to accommodate missing data in problem behavior and IQ. Under the assumption that the data are missing at random (MAR), FIML can estimate parameters using any available information that is contained in the dataset. (If data are MAR, the missing data generating mechanism is driven by observed/available information in the data.) It is also considered superior to 
other techniques used to handle missing data in terms of bias and the sampling variability of the parameter estimates produced [52]. To avoid model convergence to local maxima, we increased the number of random starts $(250$ random sets with 50 optimizations carried out in the final stage). We adjusted for the child's exact age at the baseline assessment.

We followed a classic three-step analysis whereby, upon selection of the optimal latent class model, the latent class variable was extracted and used as an observed variable for further testing [53]. (One-step approaches whereby the latent class variable is extracted and examined in terms of its associations with covariates and outcomes in the same analytical step are frequently used, but they can be problematic when examining a large number of covariates [54]. In addition, simulations have shown that in models with high entropy values the covariates do not influence class assignment drastically [55].) Upon examination of the distribution of the covariates across the extracted classes, we ran a series of regression models to measure the associations between class membership and the outcomes at age 11. We ran linear, logistic, ordered logistic and multinomial regression models, depending on the scale of measurement of each outcome. These regression models were adjusted for covariates. To handle missing data on them, we used multiple imputation (MI) and not FIML to more flexibly bring into the imputation phase auxiliary variables that maximize the plausibility of the MAR assumption. By including auxiliary variables at both the imputation and analytic stages, MI was performed using the same model specification as the one used in the fully adjusted regression analyses. Thus, we ensured the congeniality between the imputation and the analysis models and increased the likelihood that the MAR assumption was met. We generated 25 imputed datasets using sequential regression models [56].

\section{Results}

Table S1, presented in the Supplementary Material, summarizes the sex-stratified pairwise correlation coefficients and descriptive statistics of internalizing problems, externalizing problems and IQ at children's ages 3, 5, 7 and 11 years. Internalizing and externalizing problems were positively correlated with each other and negatively with IQ (all $p$ values $<0.01$ ). In addition, all three measures showed temporal stability across sexes with Pearson's correlation coefficients ranging $0.32-0.58$ for internalizing problems, $0.47-0.70$ for externalizing problems and $0.34-0.61$ for IQ (all $p$ values $<0.01$ ).

\section{Parallel-process growth mixture model}

In total, data from 16,844 ( $51 \%$ male) children were used in the parallel-process GMM. The fit indices of the competing GMMs are summarized in Table S2 in the Supplementary Material. Starting with the one-class model, stepwise additions of classes resulted in lower BIC, AIC and SSA-BIC values, suggesting better model fit to the data for higherclass solutions. However, the five- and six-class models included several small classes. The four-class solution also had a higher entropy value (0.88) compared to the five- or six-class solutions. Therefore, we considered the four-class solution optimal. In the four-class model, the average latent class (posterior) probabilities for the most likely latent class allocation ranged from 80 to $93 \%$ in males and 75 to $94 \%$ in females, indicating minimal ambiguity in class assignment.

Figures 1 and 2 illustrate the parallel trajectories of problem behavior and IQ across the four classes. Table 1 presents the growth estimates of each trajectory. In both males and females, we identified the following classes. (1) A class comprising typically developing children (81\% of males and $84 \%$ of females) with persistently low levels of internalizing and externalizing problems and with IQ scores above the sample average throughout the study period. (2) A class comprising children (6\% of males and $7 \%$ of females) with high levels of internalizing and externalizing problems at baseline, which, however, decreased rapidly and significantly ('improvers'). The IQ of males in this class was approximately one SD below the total sample mean at baseline (intercept $=87.48$, $p<0.001$ ), but was increasing with an average linear rate of 2.5 points at each assessment $($ slope $=2.45, p<0.001$ ). The IQ of their female counterparts was also low at baseline (intercept $=91.79, p<0.001$ ), yet the mean slope value did not reach statistical significance (slope $=0.54, p>0.05$ ), suggesting that females' IQ scores remained stable in this group. (3) A class comprising children with positive and highly significant slope values for both problem domains ( $p$ values $<0.01$ ), suggesting steadily increasing internalizing and externalizing problem scores during the 8-year study period ('deteriorators'). The IQ of both males and females in this class was persistently low (intercepts $=92.62$ and 93.32, respectively; $p$ values of slopes $>0.05$ ) across assessments. (4) A class comprising children with low levels of IQ and high levels of internalizing and externalizing problem scores ('troubled'). Internalizing problems in males in this group were increasing at each assessment (slope $=1.13, p<0.01$ ), while females showed very slowly decreasing levels of externalizing problems (slope $=-0.56, p<0.01$ ). Both sexes had IQ scores consistently below the sample mean across assessments. (Note: the average IQ trajectory presented in the figures is the mean estimated trajectory conditional on the behavior trajectories. As a result, it was unlikely that it 


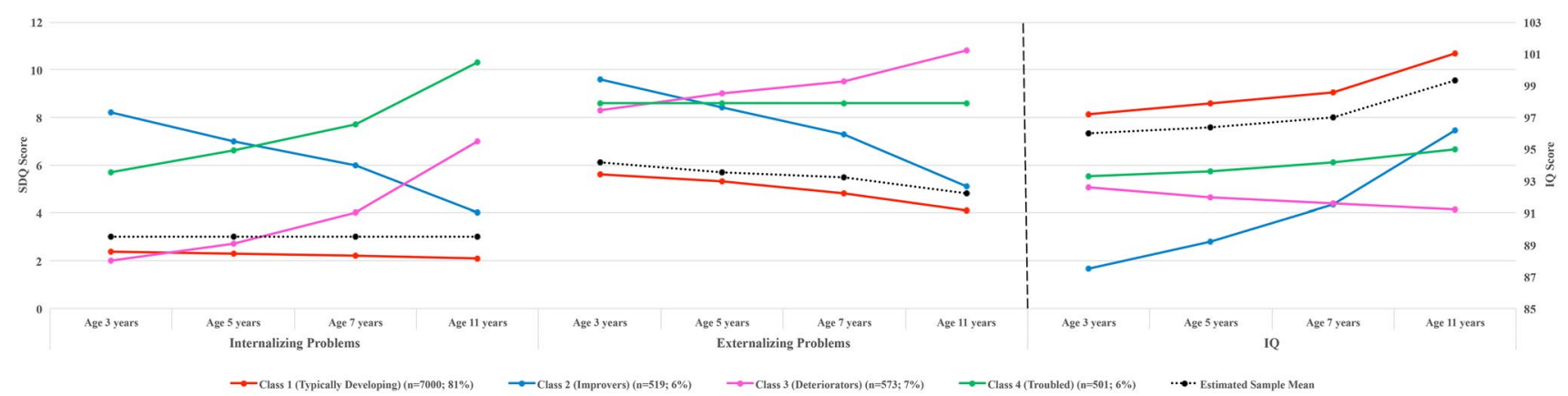

Fig. 1 Four-class solution of the three-parallel-process growth mixture model showing the parallel developmental trajectories of SDQ internalizing problems, SDQ externalizing problems and IQ from ages 3-11 years in males

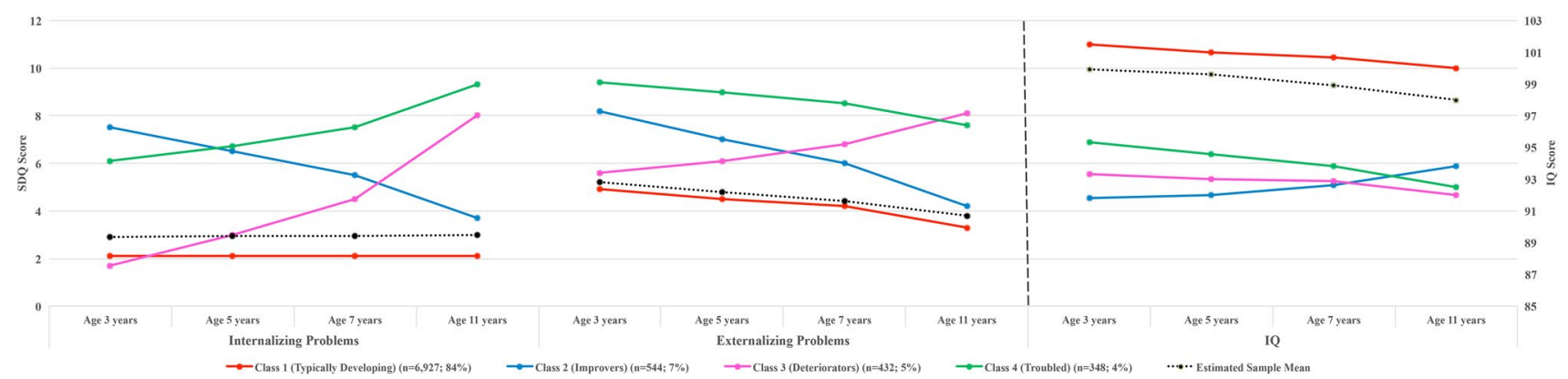

Fig. 2 Four-class solution of the three-parallel-process growth mixture model showing the parallel developmental trajectories of SDQ internalizing problems, SDQ externalizing problems and IQ from ages 3-11 years in females

would overlap perfectly with the mean observed IQ trajectory computed independently of the co-developing behavior trajectories.)

Visual inspection of the data in the figures suggested that the trajectories were linear. We tested this formally by fitting a four-class parallel-process GMM including a quadratic growth parameter. The entropy of the GMM with the quadratic growth parameter was comparable $(0.87)$ to the one without. We also tested the concordance rate of class allocation between the two competing GMMs by a kappa agreement coefficient. The results showed a concordance rate of 92 and $93 \%$ for class allocation in males and females, respectively, suggesting that the two GMMs yield almost identical classifications.

Finally, we tested for non-response bias in the analytic sample by comparing those with complete data on all outcome measures across all time points $(N=8201)$ with those with some missingness in the outcomes $(N=8643)$ on key baseline (age 3) characteristics. As expected, there was bias. Children with complete data in all outcome measures had higher IQ scores $(M=102.72, \mathrm{SE}=0.16)$ compared to those without $(M=96.05, \mathrm{SE}=0.21)$. In addition, they scored, on average, 0.53 and 0.86 points lower on the internalizing and externalizing problem scales, respectively $(p<0.001)$. They were also more likely to live with both biological parents
( $84 \%$ vs. $75 \%, p<0.001)$, had a higher mean birth weight (mean difference was $0.08 \mathrm{~kg}, p<0.01$ ) and experienced less socioeconomic disadvantage $(p<0.001)$.

\section{Outcomes in early adolescence}

We fitted regression models on the sample of 13,058 (50\% male) children with available data in at least one of the outcomes considered at age 11 years. Those excluded were predominantly male $(p=0.001)$ and had both higher levels of internalizing and externalizing problems and lower levels of IQ scores at all assessments (all $p$ values $\leq 0.001$ ). However, the proportion of children with valid data on the outcomes was similarly distributed across classes, ranging from 75 to $93 \%$.

Tables 2 and 3 summarize the characteristics of the sample by class membership and sex. Overall, at age 3 typically developing females and males experienced less socioeconomic disadvantage and more parental involvement, had older, more educated and less distressed mothers, enjoyed better child-parent relationships, lived in less chaotic homes, were less harshly disciplined and were more likely to live with both biological parents and have regular bedtimes, compared to the remaining three classes (all $p$ values $<0.01)$. As the tables show, there were also many 
Table 1 Growth estimates [intercept $(I)$ and slope $(S)$ and associated standard error (SE)] of internalizing problems, externalizing problems and IQ, stratified by class membership and sex

\begin{tabular}{|c|c|c|c|c|c|c|}
\hline & \multicolumn{2}{|c|}{ Internalizing problems } & \multicolumn{2}{|c|}{ Externalizing problems } & \multicolumn{2}{|l|}{ IQ } \\
\hline & $I(\mathrm{SE})$ & $S(\mathrm{SE})$ & $I(\mathrm{SE})$ & $S(\mathrm{SE})$ & $I(\mathrm{SE})$ & $S(\mathrm{SE})$ \\
\hline \multicolumn{7}{|l|}{ Males } \\
\hline Typically developing & $2.33(0.06)$ & $-0.06(0.01)$ & $5.71(0.09)$ & $-0.41(0.02)$ & $97.36(0.49)$ & $0.87(0.11)$ \\
\hline Improvers & $8.20(0.29)$ & $-1.10(0.09)$ & $9.57(0.34)$ & $-1.18(0.11)$ & $87.48(1.51)$ & $2.45(0.39)$ \\
\hline Deteriorators & $2.03(0.18)$ & $1.39(0.11)$ & $8.24(0.32)$ & $0.72(0.09)$ & $92.62(1.17)$ & $-0.34(0.41)$ \\
\hline Troubled & $5.79(0.37)$ & $1.13(0.16)$ & $8.55(0.33)$ & $-0.01(0.11)$ & $93.38(1.46)$ & $0.45(0.43)$ \\
\hline \multicolumn{7}{|l|}{ Females } \\
\hline Typically developing & $2.14(0.06)$ & $0.02(0.02)$ & $4.91(0.09)$ & $-0.44(0.02)$ & $101.57(0.56)$ & $-0.37(0.11)$ \\
\hline Improvers & $7.52(0.27)$ & $-0.93(0.20)$ & $8.16(0.42)$ & $-1.04(0.11)$ & $91.79(1.33)$ & $0.54(0.48)$ \\
\hline Deteriorators & $1.74(0.40)$ & $1.80(0.16)$ & $5.74(0.81)$ & $0.65(0.21)$ & $93.32(1.29)$ & $-0.33(0.34)$ \\
\hline Troubled & $6.09(1.15)$ & $0.85(0.61)$ & $9.37(0.70)$ & $-0.56(0.21)$ & $95.35(1.94)$ & $-0.72(0.48)$ \\
\hline
\end{tabular}

Bold indicates $p$ values $<0.01$

differences in these characteristics between the three smaller classes (for example, we note a striking over-representation of ethnic minority children among the 'improvers'). Therefore, all these variables were adjusted for as covariates in the regression models. The variance inflation factor for these covariates ranged from 1.01 to 1.87 , suggesting that they were not highly collinear.

Tables S3-S8, presented in the Supplementary Material, summarize the results of the crude and adjusted regression models examining the relations between class membership and the age 11 outcomes. Compared to typically developing males, deteriorators were more likely to be bullies ( $\mathrm{OR}=1.80,95 \%$ CI $1.04-3.11)$, bully victims $(\mathrm{OR}=2.98,95 \%$ CI $2.19-4.06)$ or victims $(\mathrm{OR}=2.16$, 95\% CI 1.56-2.99), to skip school $(\mathrm{OR}=2.83,95 \% \mathrm{CI}$ 1.95-2.11), to dislike school (OR $=1.75,95 \%$ CI 1.34-2.27), to be unhappy ( $\mathrm{OR}=2.97,95 \% \mathrm{CI} 2.25-3.92)$, to engage in antisocial behaviors $(\mathrm{OR}=1.94,95 \%$ CI $1.54-2.55)$, to smoke or drink $(\mathrm{OR}=1.59,95 \%$ CI $1.15-2.20)$ and to report lower self-esteem $(b=0.62, \mathrm{SE}=0.16)$. Troubled males showed less delay aversion, lower quality of decision-making and poorer risk adjustment, compared to typically developing males. They were also more likely to be bully victims $(\mathrm{OR}=2.16,95 \%$ CI $1.57-2.98)$ or victims $(\mathrm{OR}=2.38,95 \% \mathrm{CI} 1.68-3.37)$, to dislike school $(\mathrm{OR}=1.54$, 95\% CI $1.16-2.05)$, to be unhappy (OR $=2.56,95 \%$ CI $1.87-3.50)$, to engage in antisocial behaviors $(\mathrm{OR}=1.52$, 95\% CI 1.14-2.02) and to have lower self-esteem $(b=0.71$, $\mathrm{SE}=0.17)$. The outcomes of the improver males, generally not different from those of their typically developing peers, were in fact better for antisocial behaviors (OR $=0.66,95 \%$ CI 0.48-0.91).

Among females, those classified as deteriorators differed significantly from their typically developing peers in all decision-making outcomes considered. Specifically, they had higher scores in risk taking, delay aversion, deliberation time and overall proportion bet, and significantly lower scores in quality of decision-making and risk adjustment (all $p$ values $<0.05$ ). In addition, they were more likely to be bully victims $(\mathrm{OR}=2.34,95 \%$ CI $1.62-3.37)$ or victims $(\mathrm{OR}=2.74,95 \%$ CI $1.99-3.78)$, to skip school $(\mathrm{OR}=2.22,95 \%$ CI 1.17-4.22), to dislike school $(\mathrm{OR}=1.92$, 95\% CI $1.48-2.50)$, to be unhappy (OR $=2.76,95 \% \mathrm{CI}$ 2.12-3.59), to engage in antisocial behaviors $(\mathrm{OR}=1.95$, 95\% CI 1.44-2.65) and to have lower self-esteem $(b=0.71$, $\mathrm{SE}=0.17)$. Troubled females scored higher on delay aversion and lower on risk adjustment, compared to typically developing females. Moreover, they were significantly more likely to be bully victims $(\mathrm{OR}=1.76,95 \% \mathrm{CI}$ $1.11-2.79)$ or victims (OR $=2.70,95 \%$ CI $1.90-3.84)$, to skip school ( $\mathrm{OR}=4.15,95 \%$ CI 2.14-8.04), to dislike school $(\mathrm{OR}=1.51,95 \%$ CI $1.08-2.10)$, to be unhappy $(\mathrm{OR}=1.90$, 95\% CI 1.30-2.78) and to have lower self-esteem $(b=0.54$, $\mathrm{SE}=0.20$ ). Finally, females classified as improvers were more likely to skip school (OR $=2.35,95 \%$ CI $1.24-4.43)$, to be unhappy ( $\mathrm{OR}=1.47,95 \% \mathrm{CI} 1.06-2.06)$ and to have lower self-esteem $(b=0.44, \mathrm{SE}=0.17)$, compared to their typically developing peers.

\section{Children with intellectual disability (ID)}

At age 3, none of the children participating in MCS had IQ scores below 55. Thus, there were no children with moderate or severe ID at baseline in our sample. [DSM-IV classifies ID (mental retardation) into four stages based on severity: mild (IQ score of 50-55 to approximately 70), moderate (IQ score of 30-35 to 50-55), severe (IQ score of 20-25 to 35-40), and profound (IQ score of less than 20-25).] Our analytic sample likely excludes children with moderate or severe ID, as it was conditional on cognitive assessment 
Table 2 Distribution across classes of the covariates at baseline (age 3), males (unweighted data)

\begin{tabular}{|c|c|c|c|c|c|c|c|c|c|}
\hline \multirow[t]{2}{*}{ Continuous variables } & \multirow{2}{*}{$\begin{array}{l}\text { Typically } \\
\text { developing } \\
\text { (C1) } \\
M \pm \mathrm{SD}\end{array}$} & \multicolumn{2}{|c|}{ Improvers (C2) } & \multicolumn{2}{|c|}{ Deteriorators (C3) } & \multicolumn{2}{|c|}{ Troubled (C4) } & \multirow{2}{*}{\multicolumn{2}{|c|}{$\begin{array}{l}\text { Significant pairwise comparisons } \\
\text { (Bonferroni) }\end{array}$}} \\
\hline & & \multicolumn{2}{|c|}{$M \pm \mathrm{SD}$} & \multicolumn{2}{|c|}{$M \pm \mathrm{SD}$} & \multicolumn{2}{|l|}{$M \pm \mathrm{SD}$} & & \\
\hline Socioeconomic disadvantage & $0.76(1.09)$ & \multicolumn{2}{|c|}{$1.58(1.30)$} & \multicolumn{2}{|c|}{$1.28(1.30)$} & \multicolumn{2}{|c|}{$1.23(1.23)$} & \multicolumn{2}{|c|}{$\begin{array}{l}\mathrm{C} 1<\mathrm{C} 2 ; \mathrm{C} 1<\mathrm{C} 3 ; \mathrm{C} 1<\mathrm{C} 4 ; \mathrm{C} 2>\mathrm{C} 3 ; \\
\quad \mathrm{C} 2>\mathrm{C} 4\end{array}$} \\
\hline Maternal age at birth & $28.73(5.86)$ & \multicolumn{2}{|c|}{$26.89(6.32)$} & \multicolumn{2}{|c|}{$27.20(5.97)$} & \multicolumn{2}{|c|}{$27.14(5.94)$} & \multicolumn{2}{|c|}{$\mathrm{C} 1>\mathrm{C} 2 ; \mathrm{C} 1>\mathrm{C} 3 ; \mathrm{C} 1>\mathrm{C} 4$} \\
\hline Low household chaos & $11.05(2.13)$ & \multicolumn{2}{|c|}{$10.38(2.44)$} & \multicolumn{2}{|c|}{$10.23(2.25)$} & \multicolumn{2}{|c|}{$10.20(2.52)$} & \multicolumn{2}{|c|}{$\mathrm{C} 1>\mathrm{C} 2 ; \mathrm{C} 1>\mathrm{C} 3 ; \mathrm{C} 1>\mathrm{C} 4$} \\
\hline Parent-child conflict & $16.68(5.57)$ & \multicolumn{2}{|c|}{$22.57(6.83)$} & \multicolumn{2}{|c|}{$18.95(5.89)$} & \multicolumn{2}{|c|}{$21.41(6.64)$} & \multicolumn{2}{|c|}{$\begin{array}{l}\mathrm{C} 1<\mathrm{C} 2 ; \mathrm{C} 1<\mathrm{C} 3 ; \mathrm{C} 1<\mathrm{C} 4 ; \mathrm{C} 2>\mathrm{C} 3 ; \\
\mathrm{C} 2>\mathrm{C} 4 ; \mathrm{C} 3<\mathrm{C} 4\end{array}$} \\
\hline Parent-child closeness & $33.55(2.35)$ & \multicolumn{2}{|c|}{$31.45(4.16)$} & \multicolumn{2}{|c|}{$32.84(2.84)$} & \multicolumn{2}{|c|}{$32.45(3.37)$} & \multicolumn{2}{|c|}{$\begin{array}{l}\mathrm{C} 1>\mathrm{C} 2 ; \mathrm{C} 1>\mathrm{C} 3 ; \mathrm{C} 1>\mathrm{C} 4 ; \mathrm{C} 2<\mathrm{C} 3 \\
\quad \mathrm{C} 2<\mathrm{C} 4\end{array}$} \\
\hline Maternal psychological distress & $2.93(3.42)$ & \multicolumn{2}{|c|}{$6.18(5.11)$} & \multicolumn{2}{|c|}{$4.19(4.47)$} & $5.54(4$ & & $\begin{array}{c}\mathrm{C} 1<\mathrm{C} 2 ; \mathrm{C} \\
\mathrm{C} 3<\mathrm{C} 4\end{array}$ & $\mathrm{C} 3 ; \mathrm{C} 1<\mathrm{C} 4 ; \mathrm{C} 2>\mathrm{C} 3$ \\
\hline Harsh parental discipline & $9.47(2.35)$ & 9.7 & $9(2.60)$ & 10.11 & 2.48) & $9.99(2$ & & $\mathrm{C} 1<\mathrm{C} 3$; C & $\mathrm{C} 4$ \\
\hline Categorical variables & $\begin{array}{l}\text { Typically d } \\
\text { oping }(\mathrm{C} 1)\end{array}$ & & Improvers & $(\mathrm{C} 2)$ & Deterioratc & ors (C3) & Tro & ubled (C4) & Chi square test $p$ value \\
\hline & $N(\%)$ & & $N(\%)$ & & $N(\%)$ & & $N($ & & \\
\hline Ethnicity & & & & & & & & & \\
\hline White & $5900(84 \%)$ & & $316(61 \%)$ & & $511(89 \%)$ & & 414 & $(83 \%)$ & $<0.001$ \\
\hline Mixed & $202(3 \%)$ & & $19(4 \%)$ & & $12(2 \%)$ & & & $(3 \%)$ & \\
\hline Indian & $167(2 \%)$ & & $35(7 \%)$ & & $9(2 \%)$ & & & $(2 \%)$ & \\
\hline Pakistani or Bangladeshi & $380(5 \%)$ & & $108(21 \%)$ & & $22(4 \%)$ & & & $(7 \%)$ & \\
\hline Black & $260(4 \%)$ & & $26(5 \%)$ & & $15(3 \%)$ & & & $(3 \%)$ & \\
\hline Other & $87(1 \%)$ & & $15(3 \%)$ & & $4(1 \%)$ & & & $(2 \%)$ & \\
\hline Mother has university degree & $1193(18 \%)$ & & $49(10 \%)$ & & $40(7 \%)$ & & & $(11 \%)$ & $<0.001$ \\
\hline Lives with both biological parents & $5166(82 \%)$ & & $326(69 \%)$ & & $347(69 \%)$ & & 310 & $(70 \%)$ & $<0.001$ \\
\hline Not breastfed & $2004(30 \%)$ & & $182(38 \%)$ & & $215(39 \%)$ & & 165 & $(34 \%)$ & $<0.001$ \\
\hline Low quality of emotional support & $2219(40 \%)$ & & $208(58 \%)$ & & $235(52 \%)$ & & 177 & $(47 \%)$ & $<0.001$ \\
\hline Parent reads to child daily & $3676(59 \%)$ & & $191(41 \%)$ & & $246(49 \%)$ & & 211 & $(48 \%)$ & $<0.001$ \\
\hline Irregular bedtimes & $1196(19 \%)$ & & $162(35 \%)$ & & $135(27 \%)$ & & 145 & $(33 \%)$ & $<0.001$ \\
\hline Low birth weight & $383(6 \%)$ & & $59(12 \%)$ & & $43(8 \%)$ & & & $(8 \%)$ & $<0.001$ \\
\hline Mother smokes & $1756(28 \%)$ & & $167(36 \%)$ & & $215(43 \%)$ & & 179 & $(40 \%)$ & $<0.001$ \\
\hline
\end{tabular}

Results of chi square tests for categorical variables and one-way ANOVA for continuous variables

data being available. However, for few MCS children, interviewers did not administer the cognitive assessments. This was the case if the child "has a learning disability/serious behavioral problem (e.g., severe ADHD, autism) which prevents them from carrying out the assessments', 'is unable to respond in the required manner for each assessment, e.g., reading, writing, manipulating objects', 'is not able to speak or understand English (or Welsh if applicable)' or if consent and co-operation were not forthcoming (see also [57]).

Therefore, our study could only describe the trajectories of non-ID children or children with mild ID. As expected, the lowest proportion of children with mild ID was found in the class of typically developing children (2.5\% of boys and $1.3 \%$ of girls in this class). However, the majority of children with mild ID were in the "improver" class—and not the "troubled" or "deteriorator" classes—for both males and females $(12.4 \%$ of boys and $7.5 \%$ of girls in this class had IQ scores below 70 at baseline). This finding suggests that low cognitive ability in early childhood does not condemn children to adverse outcomes in early adolescence.

\section{Discussion}

In this study, we examined the unfolding and consequences of the joint development of IQ and problem behavior at ages 3-11 years in the general population. We identified four distinct patterns of this co-development. The typically developing children, the majority of the sample, had low levels of problem behavior and normal IQ. At the other extreme, the troubled children $(6 \%$ of males and $4 \%$ of females) were those with persistently low IQ and high levels 
Table 3 Distribution across classes of the covariates at baseline (age 3), females (unweighted data)

\begin{tabular}{|c|c|c|c|c|c|c|c|c|c|}
\hline \multirow[t]{2}{*}{ Continuous variables } & \multirow{2}{*}{$\begin{array}{l}\text { Typically } \\
\text { developing } \\
\text { (C1) } \\
M \pm \mathrm{SD}\end{array}$} & \multicolumn{2}{|c|}{ Improvers (C2) } & \multicolumn{2}{|c|}{ Deteriorators (C3) } & \multicolumn{2}{|c|}{ Troubled (C4) } & \multirow{2}{*}{\multicolumn{2}{|c|}{$\begin{array}{l}\text { Significant pairwise comparisons } \\
\text { (Bonferroni) }\end{array}$}} \\
\hline & & \multicolumn{2}{|c|}{$M \pm \mathrm{SD}$} & \multicolumn{2}{|c|}{$M \pm \mathrm{SD}$} & \multicolumn{2}{|l|}{$M \pm \mathrm{SD}$} & & \\
\hline Socioeconomic disadvantage & $0.79(1.11)$ & \multicolumn{2}{|c|}{$1.52(1.30)$} & \multicolumn{2}{|c|}{$1.12(1.24)$} & \multicolumn{2}{|c|}{$1.54(1.41)$} & \multicolumn{2}{|c|}{$\begin{array}{l}\mathrm{C} 1<\mathrm{C} 2 ; \mathrm{C} 1<\mathrm{C} 3 ; \mathrm{C} 1<\mathrm{C} 4 ; \mathrm{C} 2>\mathrm{C} 3 ; \\
\quad \mathrm{C} 3<\mathrm{C} 4\end{array}$} \\
\hline Maternal age at birth & $28.79(5.87)$ & \multicolumn{2}{|c|}{$26.36(6.29)$} & \multicolumn{2}{|c|}{$27.85(6.00)$} & \multicolumn{2}{|c|}{$26.88(6.01)$} & \multicolumn{2}{|c|}{$\mathrm{C} 1>\mathrm{C} 2 ; \mathrm{C} 1>\mathrm{C} 3 ; \mathrm{C} 1>\mathrm{C} 4 ; \mathrm{C} 2<\mathrm{C} 3$} \\
\hline Low household chaos & $11.23(2.09)$ & \multicolumn{2}{|c|}{$10.42(2.36)$} & \multicolumn{2}{|c|}{$10.59(2.20)$} & \multicolumn{2}{|c|}{$9.90(2.56)$} & \multicolumn{2}{|c|}{$\begin{array}{l}\mathrm{C} 1>\mathrm{C} 2 ; \mathrm{C} 1>\mathrm{C} 3 ; \mathrm{C} 1>\mathrm{C} 4 ; \mathrm{C} 2>\mathrm{C} 4 \\
\mathrm{C} 3>\mathrm{C} 4\end{array}$} \\
\hline Parent-child conflict & $16.34(5.55)$ & \multicolumn{2}{|c|}{$20.98(6.46)$} & \multicolumn{2}{|c|}{$17.60(5.58)$} & \multicolumn{2}{|c|}{$22.43(6.51)$} & \multicolumn{2}{|c|}{$\begin{array}{l}\mathrm{C} 1<\mathrm{C} 2 ; \mathrm{C} 1<\mathrm{C} 3 ; \mathrm{C} 1<\mathrm{C} 4 ; \mathrm{C} 2>\mathrm{C} 3 \\
\quad \mathrm{C} 2<\mathrm{C} 4 ; \mathrm{C} 3<\mathrm{C} 4\end{array}$} \\
\hline Parent-child closeness & $33.84(1.99)$ & \multicolumn{2}{|c|}{$32.34(4.05)$} & \multicolumn{2}{|c|}{$33.70(2.19)$} & \multicolumn{2}{|c|}{$32.67(3.28)$} & \multicolumn{2}{|c|}{$\mathrm{C} 1>\mathrm{C} 2 ; \mathrm{C} 1>\mathrm{C} 4 ; \mathrm{C} 2<\mathrm{C} 3 ; \mathrm{C} 3>\mathrm{C} 4$} \\
\hline Maternal psychological distress & $2.82(3.26)$ & \multicolumn{2}{|c|}{$6.07(5.35)$} & \multicolumn{2}{|c|}{$4.33(4.50)$} & $5.99(5$ & & $\begin{array}{c}\mathrm{C} 1<\mathrm{C} 2 ; \mathrm{C} \\
\mathrm{C} 3<\mathrm{C} 4\end{array}$ & $\mathrm{C} 3 ; \mathrm{C} 1<\mathrm{C} 4 ; \mathrm{C} 2>\mathrm{C} 3$ \\
\hline Harsh parental discipline & $9.04(2.34)$ & 9.2 & $2(2.65)$ & 9.52 & 2.48) & $9.97(2$ & & $\mathrm{C} 1<\mathrm{C} 3$; C & $\mathrm{C} 4 ; \mathrm{C} 2<\mathrm{C} 4$ \\
\hline Categorical variables & $\begin{array}{l}\text { Typically d } \\
\text { oping }(\mathrm{C} 1)\end{array}$ & & Improvers & $(\mathrm{C} 2)$ & Deterioratc & ors (C3) & Tro & ubled (C4) & Chi square test $p$ value \\
\hline & $N(\%)$ & & $N(\%)$ & & $N(\%)$ & & $N($ & & \\
\hline Ethnicity & & & & & & & & & \\
\hline White & $5836(84 \%)$ & & $342(63 \%$ & & $374(87 \%)$ & & 285 & $(82 \%)$ & $<0.001$ \\
\hline Mixed & $209(3 \%)$ & & $15(3 \%)$ & & $16(4 \%)$ & & & $(4 \%)$ & \\
\hline Indian & $170(2 \%)$ & & $23(4 \%)$ & & $6(1 \%)$ & & & $(2 \%)$ & \\
\hline Pakistani or Bangladeshi & $395(6 \%)$ & & $119(22 \%)$ & & $21(5 \%)$ & & & $(7 \%)$ & \\
\hline Black & $231(3 \%)$ & & $26(5 \%)$ & & $9(2 \%)$ & & & $(3 \%)$ & \\
\hline Other & $83(1 \%)$ & & $19(3 \%)$ & & $6(1 \%)$ & & & $(2 \%)$ & \\
\hline Mother has university degree & $1242(19 \%)$ & & $29(6 \%)$ & & $41(10 \%)$ & & & $(9 \%)$ & $<0.001$ \\
\hline Lives with both biological parents & $5119(82 \%)$ & & $362(74 \%)$ & & $284(75 \%)$ & & 189 & $(59 \%)$ & $<0.001$ \\
\hline Not breastfed & $2072(31 \%)$ & & $207(41 \%)$ & & $152(37 \%)$ & & 136 & $(42 \%)$ & $<0.001$ \\
\hline Low quality of emotional support & $2041(37 \%)$ & & $206(53 \%)$ & & $147(45 \%)$ & & 135 & $(49 \%)$ & $<0.001$ \\
\hline Parent reads to child daily & $3783(61 \%)$ & & $216(44 \%)$ & & $203(54 \%)$ & & 162 & $(51 \%)$ & $<0.001$ \\
\hline Irregular bedtimes & $1242(20 \%)$ & & $176(36 \%)$ & & $85(22 \%)$ & & 116 & $(36 \%)$ & $<0.001$ \\
\hline Low birth weight & $455(7 \%)$ & & $76(15 \%)$ & & $52(13 \%)$ & & & $(8 \%)$ & $<0.001$ \\
\hline Mother smokes & $1700(27 \%)$ & & $172(35 \%)$ & & $141(37 \%)$ & & 145 & $(46 \%)$ & $<0.001$ \\
\hline
\end{tabular}

Results of chi square tests for categorical variables and one-way ANOVA for continuous variables

of internalizing and externalizing problems. There were two groups showing significant longitudinal change in problem behavior. The first included $7 \%$ of males and $5 \%$ of females (deteriorators) with low IQ and steadily increasing internalizing and externalizing problems. Like the troubled group, these children were at risk of multiple adverse outcomes in early adolescence. The second included $6 \%$ of males and $7 \%$ of females (improvers) with initially high levels of internalizing and externalizing problems that decreased steadily during the study period, reaching the normal range by age 11 years, and low (but rapidly increasing in males) IQ scores. The males in this group had outcomes similar to, or even better than, those of their typically developing peers. The females were as likely as their typically developing peers to engage in risky or antisocial behaviors, although they were, in general, unhappier.
The patterns of the longitudinal association between internalizing and externalizing problems we found in this study resemble previous classifications of developmental patterns of internalizing and externalizing problems in childhood and adolescence $[6,11,58]$. These show that emotional and behavioral problems are largely stable throughout childhood for the majority of children, but also identify subgroups of children with increasing or decreasing symptoms. The findings of our study suggest that this typology holds in MCS too, with the majority of our sample showing either persistently low or persistently high symptom levels throughout childhood. Both in these groups and in the two groups with changing symptoms over time, internalizing and externalizing problems appeared to be positively inter-related and to develop largely in parallel, in line with previous research 
suggesting high levels of comorbid externalizing and internalizing problems in childhood $[6,59]$.

Our study also showed an inverse relation between problem behavior and IQ, in line with much evidence for low cognitive skills among children with emotional and behavioral difficulties [20, 60-62]. However, it also showed that the development of problem behavior and IQ was symmetric only for some (especially male) children. Importantly, the small minority of at-risk males with parallel improvement of ability and behavior had outcomes similar to those of their typically developing peers.

\section{Strengths and limitations}

This was the first study to examine the parallel (joint) developmental trajectories of problem behavior and IQ in the general child population, and to explore their links with a range of later social, emotional and behavioral outcomes. Its additional strengths are its large sample size and the prospectively collected data from toddlerhood until the end of primary school. However, the study has some important limitations too. First, it did not explicitly control for parental IQ or paternal mental health. Arguably, we accounted for much of the influence of both, however, by adjusting for maternal mental health (associated with paternal mental health) and education (linked to both IQ and, due to assortative mating, paternal education). Second, it did not control for changes in parental mental health or parenting behavior over the observation period, or for changes in family circumstances after age 3 . Third, it could not account for genetic influences on children's trajectories. Fourth, it was based on a sample that despite its provenance ended up being selective. For example, there was evidence for non-response bias. An additional source of bias in MCS is attrition due to dropout, death or other factors. Attrition rates in each sweep have been consistently higher for families in areas with high proportions of ethnic minorities or disadvantage compared with families in more advantaged areas [63]. However, we attempted to minimize the effect of such bias by using stateof-the-art methods of handling missing data. Fifth, it was unable to allow for the effects of clinical diagnoses (and their treatment or lack thereof), which may be particularly significant for the three atypical groups we identified [64]. Finally, some of the analyses may have been underpowered (for example, the ones predicting truancy due to the low endorsement of positive responses).

\section{Conclusions}

This study explored how IQ and problem behavior (internalizing and externalizing problems) in the general child population are related across development (ages 3-11 years).
In general, it showed evidence for an asymmetric longitudinal relationship between IQ and problem behavior in most children. The small minority of at-risk children who showed parallel improvement of behavior and cognitive ability had outcomes that were identical to, or even better than, those of their typically developing peers. Their outcomes were also significantly better than those of at-risk children with improvements only in behavior. Together, these findings suggest that interventions to improve behavior and cognitive skills in children at risk may be particularly effective in improving their later outcomes and life chances. Future studies should test this formally. They could also test if differences in outcomes remain when outcomes are located further in time, and what factors might explain how behavior and cognitive ability co-develop in children in the first place.

Acknowledgements This study was supported by Grant ES/N007921/1 from the Economic and Social Research Council.

\section{Compliance with ethical standards}

Conflict of interest On behalf of all authors, the corresponding author states that there is no conflict of interest.

Open Access This article is distributed under the terms of the Creative Commons Attribution 4.0 International License (http://creativeco mmons.org/licenses/by/4.0/), which permits unrestricted use, distribution, and reproduction in any medium, provided you give appropriate credit to the original author(s) and the source, provide a link to the Creative Commons license, and indicate if changes were made.

\section{References}

1. Deary IJ, Whiteman MC, Starr JM, Whalley LJ, Fox HC (2004) The impact of childhood intelligence on later life: following up the Scottish mental surveys of 1932 and 1947. J Pers Soc Psychol 86:130-147. https://doi.org/10.1037/0022-3514.86.1.130

2. Feinstein L, Bynner J (2004) The importance of cognitive development in middle childhood for adulthood socioeconomic status, mental health, and problem behavior. Child Dev 75:1329-1339. https://doi.org/10.1111/j.1467-8624.2004.00743.x

3. Fergusson DM, John Horwood L, Ridder EM (2005) Show me the child at seven: the consequences of conduct problems in childhood for psychosocial functioning in adulthood. J Child Psychol Psychiatry 46:837-849. https://doi.org/10.1111/j.1469-7610.2004.00387 .x

4. Keiley MK, Bates JE, Dodge KA, Pettit GS (2000) A crossdomain growth analysis: externalizing and internalizing behaviors during 8 years of childhood. J Abnorm Child Psychol 28:161-179. https://doi.org/10.1023/A:1005122814723

5. von Stumm S, Plomin R (2015) Socioeconomic status and the growth of intelligence from infancy through adolescence. Intelligence 48:30-36. https://doi.org/10.1016/j.intell.2014.10.002

6. Nivard MG, Lubke GH, Dolan CV, Evans DM, Pourcain BS, Munafò MR, Middeldorp CM (2017) Joint developmental trajectories of internalizing and externalizing disorders between childhood and adolescence. Dev Psychopathol 29:1-10. https://doi. org/10.1017/S0954579416000572 
7. Davis S, Votruba-Drzal E, Silk JS (2015) Trajectories of internalizing symptoms from early childhood to adolescence: associations with temperament and parenting. Soc Dev 24:501-520. https:// doi.org/10.1111/sode.12105

8. Dekker MC, Ferdinand RF, Van Lang ND, Bongers IL, Van Der Ende J, Verhulst FC (2007) Developmental trajectories of depressive symptoms from early childhood to late adolescence: gender differences and adult outcome. J Child Psychol Psychiatry 48:657-666. https://doi.org/10.1111/j.1469-7610.2007.01742.x

9. Haltigan JD, Roisman GI, Susman EJ, Barnett-Walker K, Monahan KC (2011) Elevated trajectories of externalizing problems are associated with lower awakening cortisol levels in midadolescence. Dev Psychol 47:472-478. https://doi.org/10.1037/a0021 911

10. Kjeldsen A, Nilsen W, Gustavson K, Skipstein A, Melkevik O, Karevold EB (2016) Predicting well-being and internalizing symptoms in late adolescence from trajectories of externalizing behavior starting in infancy. J Res Adolesc 26:991-1008. https:// doi.org/10.1111/jora.12252

11. Lancefield KS, Raudino A, Downs JM, Laurens KR (2016) Trajectories of childhood internalizing and externalizing psychopathology and psychotic-like experiences in adolescence: a prospective population-based cohort study. Dev Psychopathol 28:527-536. https://doi.org/10.1017/S0954579415001108

12. Larsson H, Dilshad R, Lichtenstein P, Barker ED (2011) Developmental trajectories of DSM-IV symptoms of attention-deficit/ hyperactivity disorder: genetic effects, family risk and associated psychopathology. J Child Psychol Psychiatry 52:954-963. https ://doi.org/10.1111/j.1469-7610.2011.02379.x

13. Letcher P, Smart D, Sanson A, Toumbourou JW (2009) Psychosocial precursors and correlates of differing internalizing trajectories from 3 to 15 years. Soc Dev 18:618-646. https://doi.org/10.111 1/j.1467-9507.2008.00500.x

14. Toumbourou JW, Williams I, Letcher P, Sanson A, Smart D (2011) Developmental trajectories of internalising behaviour in the prediction of adolescent depressive symptoms. Aust J Psychol 63:214-223. https://doi.org/10.1111/j.1742-9536.2011.00023.x

15. Weeks M, Cairney J, Wild TC, Ploubidis GB, Naicker K, Colman I (2014) Early-life predictors of internalizing symptom trajectories in Canadian children. Depress Anxiety 31:608-616. https://doi. org/10.1002/da.22235

16. Lilienfeld SO (2003) Comorbidity between and within childhood externalizing and internalizing disorders: reflections and directions. J Abnorm Child Psychol 31:285-291. https://doi. org/10.1023/A:1023229529866

17. Pennington BF, Ozonoff S (1996) Executive functions and developmental psychopathology. J Child Psychol Psychiatry 37:51-87. https://doi.org/10.1111/j.1469-7610.1996.tb01380.x

18. Plomin R, Price TS, Eley TC, Dale PS, Stevenson J (2002) Associations between behaviour problems and verbal and nonverbal cognitive abilities and disabilities in early childhood. J Child Psychol Psychiatry 43:619-633. https://doi.org/10.1111/1469-7610.00051

19. De Ruiter KP, Dekker MC, Verhulst FC, Koot HM (2007) Developmental course of psychopathology in youths with and without intellectual disabilities. J Child Psychol Psychiatry 48:498-507. https://doi.org/10.1111/j.1469-7610.2006.01712.x

20. Skogli EW, Egeland J, Andersen PN, Hovik KT, Øie M (2014) Few differences in hot and cold executive functions in children and adolescents with combined and inattentive subtypes of ADHD. Child Neuropsychol 20:162-181. https://doi.org/10.1080/09297 049.2012.753998

21. Cheng ER, Palta M, Kotelchuck M, Poehlmann J, Witt WP (2014) Cognitive delay and behavior problems prior to school age. Pediatrics 134:e749-e757. https://doi.org/10.1542/peds.2014-0259

22. Emerson E (2003) Prevalence of psychiatric disorders in children and adolescents with and without intellectual disability. J Intellect Disabil Res 47:51-58. https://doi.org/10.1 046/j.1365-2788.2003.00464.x

23. Emerson E, Hatton C (2007) Mental health of children and adolescents with intellectual disabilities in Britain. Br J Psychiatry 191:493-499. https://doi.org/10.1192/bjp.bp.107.038729

24. Fanti KA, Henrich CC (2010) Trajectories of pure and cooccurring internalizing and externalizing problems from age 2 to age 12: findings from the National Institute of Child Health and Human Development Study of Early Child Care. Dev Psychol 46:1159-1175. https://doi.org/10.1037/a0020659

25. Patalay P, Moulton V, Goodman A, Ploubidis GB (2017) Crossdomain symptom development typologies and their antecedents: results from the UK millennium cohort study. J Am Acad Child Adolesc Psychiatry 56:765-776. https://doi.org/10.1016/j. jaac.2017.06.009

26. Flouri E, Midouhas E, Joshi H (2015) Family and neighbourhood risk and children's problem behaviour: the moderating role of intelligence. Intelligence 53:33-42. https://doi.org/10.1016/j. intell.2015.08.003

27. Bracken BA (1998) Bracken basic concept scale: revised. The Psychological Corporation, Harcourt Brace and Company, San Antonio

28. Elliott CD, Smith P, McCulloch K (1996) British ability scales second edition (BAS II). Administration and scoring manual. Nelson, London

29. Hanscombe KB, Trzaskowski M, Haworth CM, Davis OS, Dale PS, Plomin R (2012) Socioeconomic status (SES) and children's intelligence (IQ): in a UK-representative sample SES moderates the environmental, not genetic, effect on IQ. PLoS One 7:e30320. https://doi.org/10.1371/journal.pone.0030320

30. Johnson W, Bouchard TJ, Krueger RF, McGue M, Gottesman II (2004) Just one g: consistent results from three test batteries. Intelligence 32:95-107. https://doi.org/10.1016/S0160-2896(03)00062-X

31. Goodman R (1997) The strengths and difficulties questionnaire: a research note. J Child Psychol Psychiatry 38:581-586. https:// doi.org/10.1111/j.1469-7610.1997.tb01545.x

32. Goodman A, Lamping DL, Ploubidis GB (2010) When to use broader internalising and externalising subscales instead of the hypothesised five subscales on the strengths and difficulties questionnaire (SDQ): data from British parents, teachers and children. J Abnorm Child Psychol 38:1179-1191. https://doi.org/10.1007/ s10802-010-9434-x

33. Rogers RD, Owen AM, Middleton HC, Williams EJ, Pickard JD, Sahakian BJ, Robbins TW (1999) Choosing between small, likely rewards and large, unlikely rewards activates inferior and orbital prefrontal cortex. J Neurosci 19:9029-9038

34. Flouri E, Ioakeimidi S, Midouhas E, Ploubidis GB (2017) Maternal psychological distress and child decision-making. J Affect Disord 218:35-40. https://doi.org/10.1016/j.jad.2017.04.034

35. Rosenberg M (1965) Society and the adolescent self-image, vol 11. Princeton University Press, Princeton

36. Eriksen H-LF, Kesmodel US, Underbjerg M, Kilburn TR, Bertrand J, Mortensen EL (2013) Predictors of intelligence at the age of 5: family, pregnancy and birth characteristics, postnatal influences, and postnatal growth. PLoS One 8:e79200. https:// doi.org/10.1371/journal.pone.0079200

37. D'Onofrio BM, Rickert ME, Langström N, Donahue KL, Coyne CA, Larsson H, Ellingson JM, Van Hulle CA, Iliadou AN, Rathouz PJ (2012) Familial confounding of the association between maternal smoking during pregnancy and offspring substance use and problems. Arch Gen Psychiatry 69:1140-1150. https://doi.org/10.1001/archgenpsychiatry.2011.2107

38. Donnellan MB, Trzesniewski KH, Robins RW, Moffitt TE, Caspi A (2005) Low self-esteem is related to aggression, antisocial behavior, and delinquency. Psychol Sci 16:328-335. https://doi. org/10.1111/j.0956-7976.2005.01535 
39. Kessler RC, Barker PR, Colpe LJ, Epstein JF, Gfroerer JC, Hiripi E, Howes MJ, Normand S-LT, Manderscheid RW, Walters EE, Zaslavsky AM (2003) Screening for serious mental illness in the general population. Arch Gen Psychiatry 60(2):184-189. https:// doi.org/10.1001/archpsyc.60.2.184

40. Malmberg LE, Flouri E (2011) The comparison and interdependence of maternal and paternal influences on young children's behavior and resilience. J Clin Child Adolesc Psychol 40:434444. https://doi.org/10.1080/15374416.2011.563469

41. Pianta R (1992) child parent relationship scale. Center for Advanced Studies on Teaching and Learning, University of Virginia, Charlottesville

42. Caldwell BM, Bradley RH (1984) Home observation for measurement of the environment. University of Arkansas, Little Rock

43. Straus MA, Hamby SL (1997) Measuring physical \& psychological maltreatment of children with the conflict tactics scales. In: Kaufman Kantor G, Jasinski JL (eds) Out of the darkness: contemporary perspectives on family violence. Sage publications, Thousand Oaks, CA. https://doi.org/10.4135/9781483328058.n10

44. Leve LD, Kim HK, Pears KC (2005) Childhood temperament and family environment as predictors of internalizing and externalizing trajectories from ages 5 to 17. J Abnorm Child Psychol 33:505-520. https://doi.org/10.1007/s10802-005-6734-7

45. Douma JC, Dekker MC, de Ruiter KP, Tick NT, Koot HM (2007) Antisocial and delinquent behaviors in youths with mild or borderline disabilities. Am J Ment Retard 112:207-220. https://doi. org/10.1352/0895-8017(2007)112[207:aadbiy]2.0.co;2

46. Carter AS, Godoy L, Wagmiller RL, Veliz P, Marakovitz S, Briggs-Gowan MJ (2010) Internalizing trajectories in young boys and girls: the whole is not a simple sum of its parts. $\mathbf{J}$ Abnorm Child Psychol 38:19-31. https://doi.org/10.1007/s1080 2-009-9342-0

47. Richer L, Lachance L, Côté A (2016) Relationship between age and psychopathological manifestations in school-age children with an intellectual disability: the role of executive functioning. DADD Online J 3:181-200

48. StataCorp (2015) Stata Statistical Software: Release 14. StataCorp LP, College Station, TX

49. Muthén LK, Muthén BO (2007) Mplus User's Guide, 6th edn. Muthén \& Muthén, Los Angeles, CA

50. Wickrama KK, Lee TK, O’Neal CW, Lorenz FO (2016) Higherorder growth curves and mixture modeling with Mplus: a practical guide. Routledge, New York

51. Jung T, Wickrama K (2008) An introduction to latent class growth analysis and growth mixture modeling. Soc Personal Psychol Compass 2:302-317. https://doi.org/10.111 1/j.1751-9004.2007.00054.x

52. Enders CK (2001) The performance of the full information maximum likelihood estimator in multiple regression models with missing data. Educ Psychol Meas 61:713-740. https://doi. org/10.1177/0013164401615001
53. Bornovalova MA, Levy R, Gratz KL, Lejuez C (2010) Understanding the heterogeneity of BPD symptoms through latent class analysis: initial results and clinical correlates among innercity substance users. Psychol Assess 22:233-245. https://doi. org/10.1037/a0018493

54. Vermunt JK (2010) Latent class modeling with covariates: two improved three-step approaches. Polit Anal 18:450-469. https:// doi.org/10.1093/pan/mpq025

55. Asparouhov T, Muthén B (2014) Auxiliary variables in mixture modeling: three-step approaches using M plus. Struct Equ Modeling 21:329-341. https://doi.org/10.1080/10705511.2014.91518 1

56. Asparouhov T, Muthén B (2010). Multiple imputation with Mplus. Technical Report. Version 2. http://www.statmodel.com/. Accessed 11 Apr 2018

57. Emerson E, Robertson J, Baines S, Hatton C (2016) Obesity in British children with and without intellectual disability: cohort study. BMC Public Health 16(1):644. https://doi.org/10.1186/ s12889-016-3309-1

58. Hauser-Cram P, Woodman AC (2016) Trajectories of internalizing and externalizing behavior problems in children with developmental disabilities. J Abnorm Child Psychol 44:811-821. https://doi. org/10.1007/s10802-015-0055-2

59. Flouri E, Midouhas E, Joshi H (2014) Family poverty and trajectories of children's emotional and behavioural problems: the moderating roles of self-regulation and verbal cognitive ability. J Abnorm Child Psychol 42:1043-1056. https://doi.org/10.1007/ s10802-013-9848-3

60. Kuntsi J, Eley T, Taylor A, Hughes C, Asherson P, Caspi A, Moffitt T (2004) Co-occurrence of ADHD and low IQ has genetic origins. Am J Med Genet B Neuropsychiatr Genet 124:41-47. https://doi.org/10.1002/ajmg.b.20076

61. McGrath LM, Pennington BF, Shanahan MA, Santerre-Lemmon LE, Barnard HD, Willcutt EG, DeFries JC, Olson RK (2011) A multiple deficit model of reading disability and attention-deficit/ hyperactivity disorder: searching for shared cognitive deficits. J Child Psychol Psychiatry 52:547-557. https://doi.org/10.111 1/j.1469-7610.2010.02346.x

62. Morin AJ, Arens AK, Maïano C, Ciarrochi J, Tracey D, Parker PD, Craven RG (2017) Reciprocal relationships between teacher ratings of internalizing and externalizing behaviors in adolescents with different levels of cognitive abilities. J Youth Adolesc 46:125. https://doi.org/10.1007/s10964-016-0574-3

63. Mostafa T, Ploubidis G (2017) Millennium cohort study. Sixth survey. 2015-2016. Technical report on response (age 14). Centre for Longitudinal Studies, London

64. Duijff SN, Klaassen PW, Swanenburg de Veye HF, Beemer FA, Sinnema G, Vorstman JA (2013) Cognitive and behavioral trajectories in 22q11DS from childhood into adolescence: a prospective 6-year follow-up study. Res Dev Disabil 34:2937-2945. https:// doi.org/10.1016/j.ridd.2013.06.001 